\title{
April 2014 Critical Care Case of the Month: Too Much, Too Fast
}

Kenneth Sakata, MD

Richard A. Helmers, MD

Department of Pulmonary Medicine

Mayo Clinic Arizona

Scottsdale, AZ

\section{History of Present IIIness}

A 69 year old man was admitted to the intensive care unit with shortness of breath and atrial fibrillation with a rapid ventricular response.

\section{$P M H, F H, S H$}

He has a history of peripheral vascular disease, end-stage renal disease and is receiving chronic hemodialysis.

\section{Physical Examination}

Afebrile. Pulse 135 and irregular. BP 105/65 mm Hg. SpO2 96\% while receiving oxygen at $2 \mathrm{~L} / \mathrm{min}$ by nasal cannula.

HEENT: Unremarkable.

Neck: Jugular venous distention to the angle of the jaw while the head is elevated at 45 degrees.

Lungs: Decreased breath sounds at the right base.

Cardiovascular: Irregularly, irregular rhythm. 2-3+ pretibial edema.

Abdomen: no hepatosplenomegaly.

\section{Radiography}

The admission chest $\mathrm{x}$-ray is shown in figure 1. 


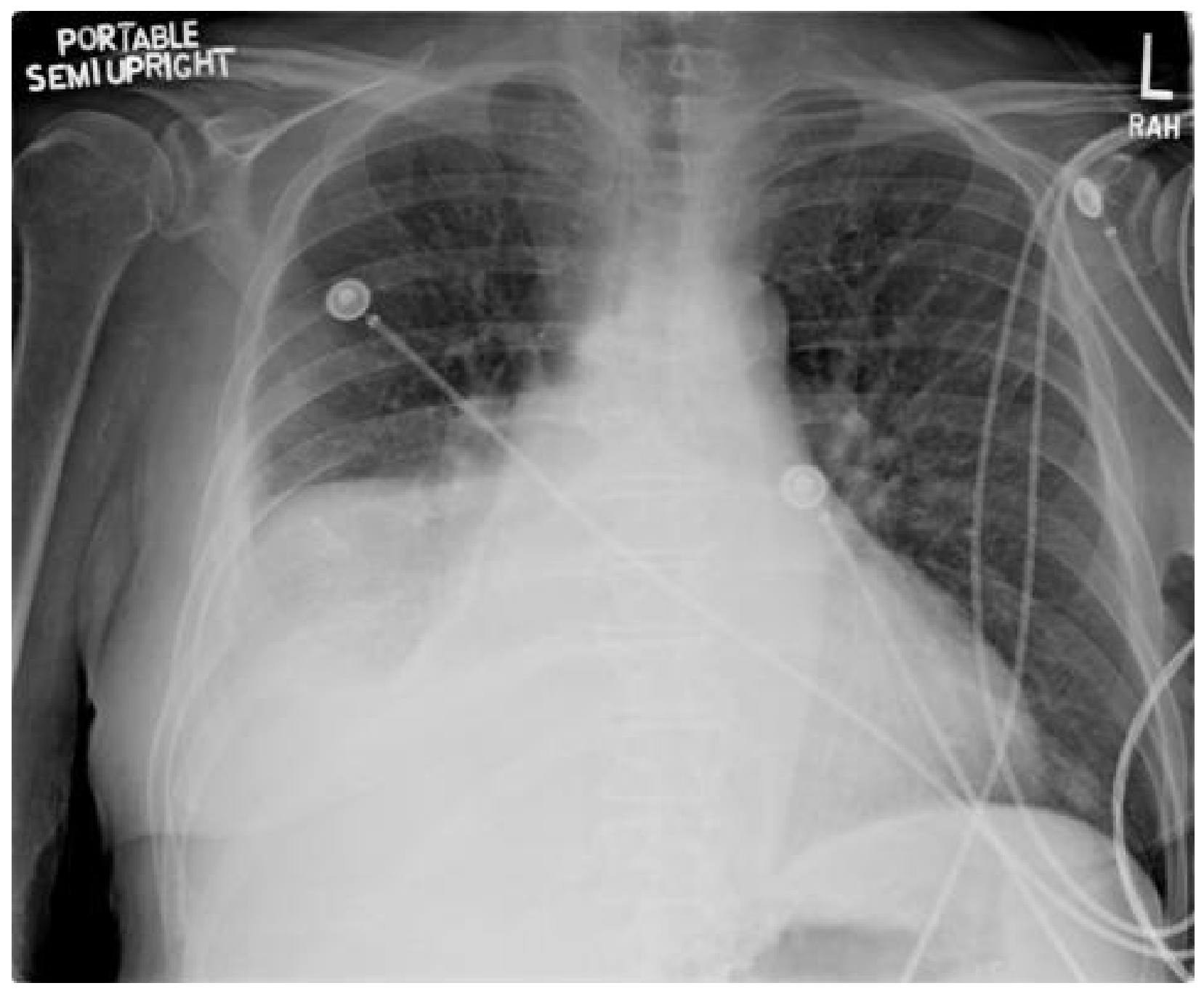

Figure 1. Admission portable chest $\mathrm{x}$-ray.

Which of the following is the best interpretation of the chest x-ray given the clinical situation?

1. Hepatomegaly elevating the right diaphragm

2. Large right pleural effusion

3. Paralyzed right diaphragm

4. Right lower lobe pneumonia

5. Right middle lobe pneumonia 


\section{Correct! \\ 2. Large right pleural effusion}

All the choices can cause an increased density on the x-ray in the right lower chest (Figure 2).

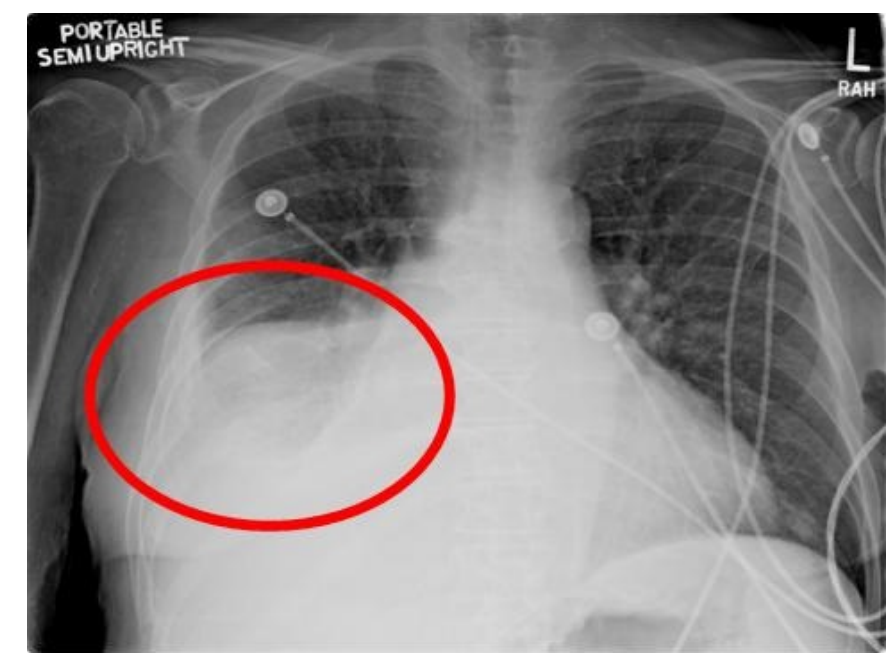

Figure 2. Admission portable chest $\mathrm{x}$-ray showing the abnormality in the right lower chest (red circle).

There is a homogenous, dense haze over the right lower chest without any evidence of air bronchograms as usually seen with a pneumonia. Given the clinical situation of a fluid-overloaded patient, this makes right pleural effusion the most likely diagnosis. This was confirmed by ultrasound (Figure 3).

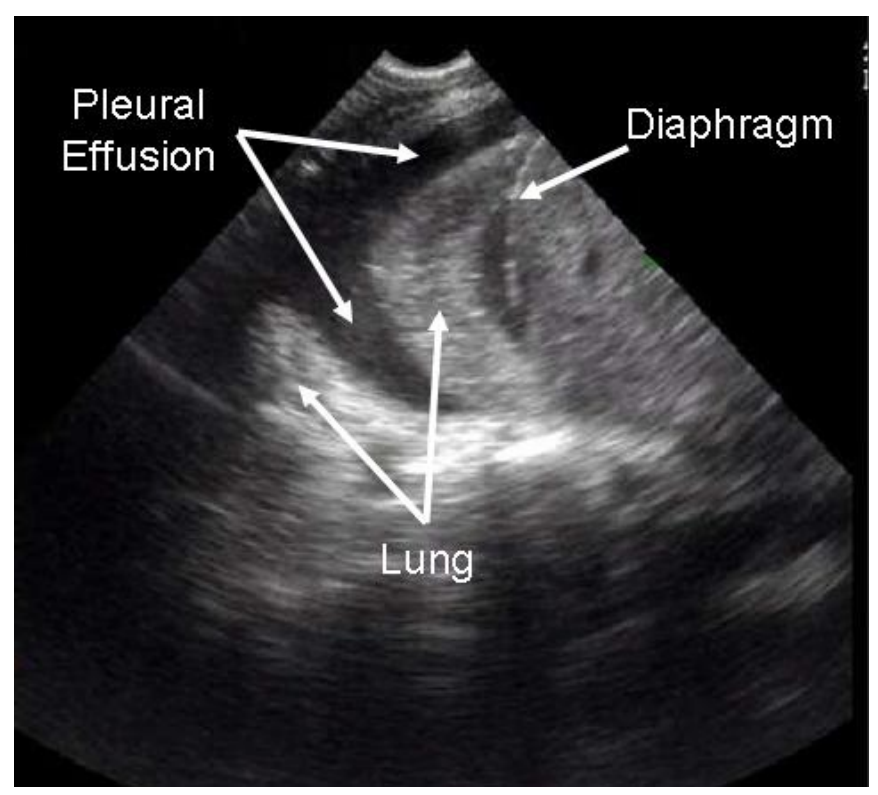

Figure 3. Right pleural view ultrasound showing pleural effusion. 
Which of the following should be done next?

1. Diuresis

2. Emergent hemodialysis

3. Observation

4. Thoracic CT scan

5. Ultrasound guided thoracentesis 


\section{Correct! \\ 5. Ultrasound guided thoracentesis}

The patient has end-stage kidney disease and so attempting diuresis with furosemide or other diuretics will likely fail. Observation in a patient with shortness of breath seems inappropriate. Both emergent hemodialysis and a thoracic CT scan could be done but seem unnecessary at this juncture.

Ultrasound guided thoracentesis was performed with 2 liters of clear, light yellow fluid removed. A chest $\mathrm{X}$-ray taken after the thoracentesis shows almost total clearing of the pleural fluid (Figure 4).

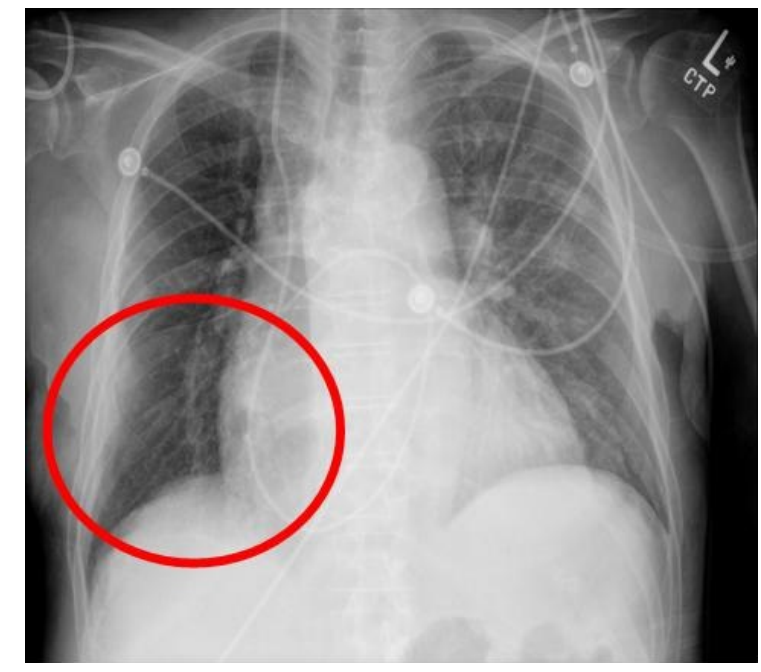

Figure 4. Chest $\mathrm{x}$-ray taken after thoracentesis showing near total clearing of the lower right lung density (red circle).

However, beginning about 3 hours after the thoracentesis the patient developed increasing dyspnea. A repeat chest x-ray was performed (Figure 5).

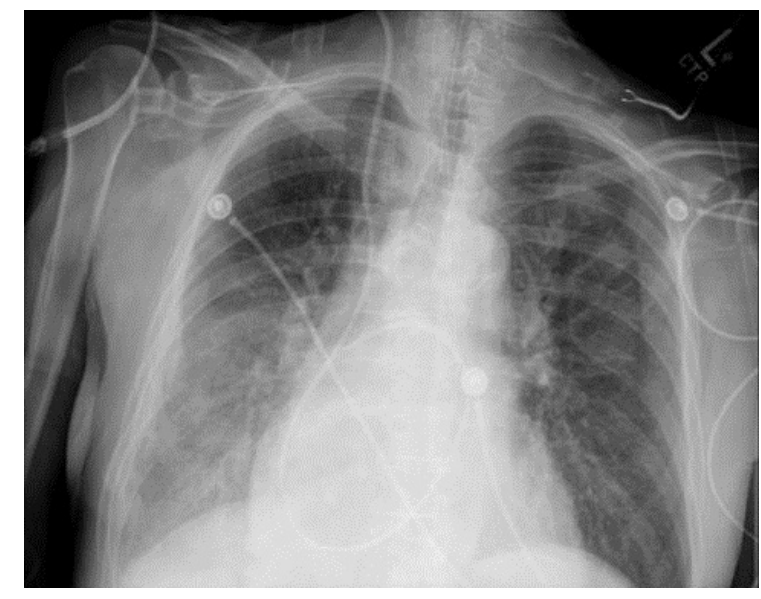

Figure 5. Chest x-ray taken about 4 hours after the thoracentesis. 
What is the most likely cause of the patient's dyspnea?

1. Reaccumulation of pleural fluid

2. Re-expansion pulmonary edema

3. Right lower lobe pneumonia

4. Right middle lobe pneumonia

5. Right pneumothorax 


\section{Correct! \\ 2. Re-expansion pulmonary edema}

The chest x-ray shows the interval development of consolidation in the right lower chest with air bronchograms and both the diaphragm and right heart border still visible. The right costophrenic angle is not blunted as would be expected with reaccumulation of pleural fluid. There is no evidence of a right pneumothorax. Both right middle and/or lower lobe pneumonia are possible but the development of consolidation temporally in relationship to the thoracentesis suggests re-expansion pulmonary edema.

Which of the following is/are true regarding re-expansion pulmonary edema?

1. Associated with rapid removal of large volumes of pleural fluid

2. Preferred treatment is diuretics, n-acetylcysteine and/or acetazolamide

3. Prevented with the use of low negative pressure during fluid removal

4. $1+3$

5. All of the above 


\section{Correct!}

\section{4. $1+3$}

The incidence of re-expansion pulmonary edema (REPE) is $0.2-14 \%$ of thoracentesis (1). Mortality is up to $20 \%$ (2). Symptoms include:

- Chest discomfort

- Persistent cough with or without frothy sputum

- Dyspnea and tachypnea

- Tachycardia

- Hypoxemia

The onset of symptoms is within 24 hours and $64 \%$ of patients have the onset of symptoms within 1-2 hours (1-3). Symptoms usually resolve within 24-72 hours.

The pathophysiology of REPE is poorly understood and likely multifactorial (2). One promising theory is that ventilation and reperfusion injury of a previously collapsed lung leads to production of reactive oxygen species and superoxide radicals resulting in increased capillary permeability.

Risk of REPE is thought to be minimal if pleural pressure is maintained above $-20 \mathrm{~cm}$ $\mathrm{H} 2 \mathrm{O}$ throughout the thoracentesis (4). Others have advocated limiting drainage to about 1-1.5L of pleural fluid to avoid REPE (1).

Treatment is largely supportive and includes supplemental oxygen for hypoxemia (1-3). Use of diuretics, bronchodilators, prostaglandin analogues, ibuprofen and steroids remains largely anecdotal (1).

\section{References}

1. Kasmani R, Irani F, Okoli K, Mahajan V. Re-expansion pulmonary edema following thoracentesis. CMAJ. 2010;182(18):2000-2. [CrossRef] [PubMed]

2. Mahfood S, Hix WR, Aaron BL, Blaes $P$, Watson DC. Reexpansion pulmonary edema. Ann Thorac Surg. 1988;45(3):340-5. [CrossRef] [PubMed]

3. Feller-Kopman D, Berkowitz D, Boiselle P, Ernst A. Large-volume thoracentesis and the risk of reexpansion pulmonary edema. Ann Thorac Surg. 2007;84(5):1656-61. [CrossRef] [PubMed]

4. Light RW, Jenkinson SG, Minh VD, George RB. Observations on pleural fluid pressures as fluid is withdrawn during thoracentesis. Am Rev Respir Dis 1980; 121:799-804. [PubMed] 